\section{PRACTICAL PROCEDURES IN CLINICAL MEDICINE}

By R. I. S. Bayliss, M.A., M.D., M.R.C.P. 2nd Edition. Pp. xvi +484 , with 6r illustrations. London: J. \& A. Churchill, Ltd. 1954. 32 s.

The recently qualified house physician often feels a sense of dismay at the variety of problems with which he is faced for which no answers have been provided during his undergraduate training. Dr. Bayliss, and his collaborators, Drs. Fearnley, Pierce, and Tovey, and Mrs. Walwyn-Jones, have written this book as a sort of vade-mecum for housemen and registrars. It contains a quite astonishing amount of information which on random sampling seems accurate and up to date. In general, the information is set out in a readily accessible and helpful way, although the reviewer cannot help wondering how much help the harassed H.P. will obtain from the section on the treatment of water and salt depletion when faced with a dehydrated patient. The problem of treatment could have been greatly simplified by the inclusion of a few electrolyte diagrams of the type introduced by Gamble. Perhaps such diagrams could be introduced in a further edition. The illustrations are mostly useful, although some are frankly unnecessary. In particular it seems a pity to have wasted three plates showing the different sizes of serum and hypodermic needles, and the drawings of blood transfusion bottles might also have been omitted. On the other hand, the section describing the performance of a differential leucocyte count would be made much more valuable by the inclusion of a coloured plate of the cells found in the peripheral blood. These are all, however, minor points, and the book is one which can be unhesitatingly recommended for those needing guidance in the practical problems of everyday clinical practice.

\section{TREPONEMATOSES}

By T. GuTHRIE, M.D., M.P.H., and R. R. Willcox, M.D. Pp. 79, with 26 illustrations.

Geneva: World Health Organization. I954.

This beautifully produced pamphlet reviews all the work done by the World Health Organization (W.H.O.) in the control of the diseases caused by treponemata: Syphilis, both endemic and venereal; yaws, and pinta being the chief. The text is illustrated with numerous excellent maps and photographs of lesions seldom seen in this country and, in fact, the pamphlet forms a useful atlas of these diseases. The authors emphasize the enormous extent of the problem and they summarize the attempts made to control these diseases in different countries. Finally the authors describe the other relevant activities of W.H.O.; amongst these being: the expert advisory panels, the W.H.O. fellowships and travel grants, the treponematosis laboratory centre, the international standardization of serological methods and reagents, and the W.H.O. serological reference laboratory.

Altogether this is a most impressive account of a most important piece of work.

\section{RECENT ADVANCES IN SURGERY}

Edited by H. C. EDwards, C.B.E., M.S., F.R.C.S. 4th Edition. Pp. xiv +480 , with 157 illustrations. London: J. \& A. Churchill Ltd. I954. 40s.

'Recent Advances in Surgery' has for many years been a necessary part of the library of the would-be surgeon, and the present edition is a most worthy member of the series. It gives a reasonable account of many new procedures which are recent enough to be collected in a textbook for the first time and old enough to be considered beyond the experimental stage. Mr. Edwards and his co-writers have expounded new concepts with enthusiasm tempered with mature judgment. The editor's discussion of gastric and biliary tree operations is admirable, as is that on recent thoracic surgery by Mr. Holmes Sellors. The little chapter on water and electrolyte metabolism is most lucid, but it is invidious to make selections from a series of articles of a uniformly high standard. Throughout the book it is possible to detect the writers' personal opinions of new operations and ideasand I fancy the future will show their judgments to be in the main wise ones.

The present edition is almost completely new; only a few of the old illustrations remain. But it is interesting to look back on the previous edition for comparison. Here were considered hopefully many procedures, such as thoraco-lumbar sympathectomy, excision of intervertebral discs, vagotomy and conservative proctosigmoidectomy which have not come up to expectations. On the other hand it did indicate the progress to come in thoracic and vascular surgery and the surgical approach to ulcerative colitis.

There is little to criticise. There are some misspellings and the $\mathrm{X}$-ray reproductions are not always clear. But these are not serious faults and this is a book that can be confidently recommended to all fellowship candidates and perhaps to not a few of their examiners as well.

J.L.S.

\section{PSYCHOLOGY, THE NURSE AND THE PATIENT}

By Doris M. Odlum, M.A., M.R.C.S., L.R.C.P., D.P.M., Dip.Ed. 2nd Edition. Pp. I68. London: Nursing Mirror. 1954. r2s. 6d.

This second edition has been increased in size and the additional chapters cover the new syllabus of the General Nursing Council.

The book is easily read and understood by Nurses just entering the profession, and will also be helpful in the final year of training.

The final chapters explain terms which are often loosely used by lay public, and the brief account on treatments will make all realise that diseases of the mind can be treated and in many cases cured.

R.K. 